\title{
JOSÉ VASCONCELOS Y LOS "GRANDES LIBROS"
}

Rafael González Díaz*

RESUMEN: La publicación de los Great Books de Hutchins y Adler proviene de los Harvard Classics, los Everyman's Library, los Oxford's World's Classics, entre otros, y del influyente pensamiento de John Henry Newman. Sin embargo, en México tienen diferentes raíces: el Ateneo de la Juventud, el grupo de los Siete Sabios y la Generación de 1915. Especial influencia ejercieron Vasconcelos, Palacios Macedo, Cosío Villegas y Gómez Morín. En esta investigación se explora el contexto y significado del proyecto Los clásicos realizado por Vasconcelos diez años antes que Hutchins en Chicago y treinta y dos antes de los Great Books of the Western World. Los "libros grandes" de Vasconcelos cambiaron el panorama cultural y educativo mexicano.

\section{yose}

ABSTRACT: Hutchins and Adler's publication of the Great Books has its origins in the Harvard Classics, the Everyman's Library, the Oxford World Classics, and the positive influence of John Henry Newman. In Mexico, however, such initiative comes from different sources, namely, the Mexican Youth Athenaeum, the Seven Sages of Mexico, and the Generation of 1915. The leading protagonists were Vasconcelos, Palacios Macedo, Cosío Villegas, and Gómez Morín. In this article, we will investigate the context and significance of the Classics project led by Vasconcelos ten years previous to that of Hutchins in Chicago and 32 years before the Great Books of the Western World. Vasconcelos" "Great Books" revolutionized the Mexican educational and cultural scene.

Palabras Clave: Vasconcelos, Los clásicos, Grandes libros, Ateneo de la juventud, Hutchins, Adler.

KEY WORDS: Vasconcelos, the Classics, Great Books, the Mexican Youth Athenaeum, Hutchins, Adler.

* Departamento Académico de Estudios Generales, ITAM. 
CITAM Derechos Reservados.

La reproducción total o parcial de este artículo se podrá hacer si el ITAM otorga la autorización previamente por escrito.

RECEPCIÓN: 04 de junio de 2013.

APROBACIÓN: 12 de junio de 2013.

Estudios 106, vol. XI, otoño 2013. 


\section{JOSÉ VASCONCELOS Y LOS "GRANDES LIBROS”}

\section{Introducción}

Robert Maynard Hutchins (18991977) y Mortimer Adler (1902-2001) son considerados, habitualmente, precursores del movimiento educativo de los estudios generales y de la publicación y difusión de los Grandes libros en Estados Unidos y en América Latina. ${ }^{1}$ Este juicio no carece de fundamento si tomamos en cuenta que, a partir de 1930, emprendieron profundas transformaciones administrativas y curriculares en la Universidad de Chicago para oponerse con firmeza al cientificismo positivista y a la excesiva profesionalización que imperaba en las universidades americanas por influencia del pragmatismo educativo de John Dewey (1859-1952). ${ }^{2}$ Incorpo-

* Este artículo se basó en la conferencia presentada en el IV Simposio de la Red Internacional de Estudios Generales (RIDEG) en la Pontificia Universidad Católica del Perú (PUCP), que se llevó a cabo del 17 al 19 de octubre de 2012.

${ }^{1}$ El término estudios generales proviene de la expresión studium generale, nombre que se le otorgó a la universidad europea en los siglos XII y XIII. Se refería a aquellas instituciones que habían alcanzado fama "internacional", y combinaban las artes liberales con alguna especialidad. Cfr. Mary Ann Dzuback, Robert M. Hutchins. Portrait of an Educator, 1991, Chicago, University of Chicago, pp. 93-107; Milton Mayer, Robert Maynard Hutchins. A Memoir, 1993, Berkeley, University of California Press, pp. 291-7.

${ }^{2}$ El estudio de la influencia de John Dewey en la filosofía de la educación en Hispanoamérica y en México se encuentra en un período de redescubrimiento. John Dewey visitó México en 1926, invitado por el Secretario de Educación Pública, Moisés Sáenz, el mismo año en que José Vasconcelos impartió una serie de conferencias en la Universidad de Chicago. Cfr. Jaime Nubiola y Beatriz Sierra, "La recepción de Dewey en España y Latinoamérica," en Utopía y praxis latinoamericana, vol. 6, núm. 13, junio, 2001, pp. 107-19; Juan Carlos 
raron en el curriculum universitario asignaturas que ofrecían a los estudiantes un acceso a los "grandes libros" en los que se concentraba el "legado intelectual de occidente", que permitía el "examen crítico de sí mismo", la libertad de pensamiento, la creatividad y el compromiso democrático. ${ }^{3}$

Este renovado cultivo de las humanidades en la Universidad de Chicago tuvo como antecedente inmediato la experiencia que se desarrollaba en la Universidad de Columbia desde 1921. En ella, el profesor John Erskine (1879-1951) preparó una selección de textos que fue conocida como Classics of Western Civilization ${ }^{4}$ e impartió el curso titulado General Honors en el que se discutía y reflexionaba sobre ellos. ${ }^{5}$ Sin embargo, la publicación y el uso pedagógico de los Grandes libros tiene una historia más antigua que se relaciona, en Estados Unidos, con los Harvard Classics (1909), ${ }^{6}$ en Inglaterra, con los Everyman's Library (1906), los Oxford's World's Classics (1901) y, entre otros, con el influyente pensamiento de John Henry Newman (1801-1890) sobre la naturaleza de la vida universitaria, que se expone en su obra The Idea of a University. ${ }^{7}$

Geneyro, La democracia inquieta: E. Durkheim y J. Dewey, 1991, Barcelona, AnthroposUniversidad Autónoma Metropolitana, p. 117; y "Educación y democracia: aportes de John Dewey”, 1994-1995, en Estudios. Filosofía. Historia. Letras, núm. 39-40, vol. XI, inviernoprimavera, pp. 77-98.

${ }^{3}$ Cfr. Robert Hutchins, Humanistic Education and Western Civilization, 1964, New York, Holt, Rinehart and Winston, pp. 1-43; Jorge Rodríguez Beruff, "El papel de los estudios generales en los estudios universitarios contemporáneos", en Estudios. Filosofia. Historia. Letras, núm. 97, vol. IX, verano 2011, pp. 25-27; Anne Stevens, "The philosophy of General Education and its contradictions: The influence of Hutchins", The Journal of General Education, vol. 50, núm. 3, 2001, pp. 165-91.

${ }^{4}$ Cfr. Jay Satterfield, The World's Best Books. Taste, Culture, and the Modern Library, 2002, Amherst, University of Massachusetts Press, pp. 60; Joan Selley Rubin, "The Scholar and the World: Academic Humanists and General Readers in Postwar America”, en David Hollinger (ed.), The Humanities and the Dynamics of Inclusion since World War II, 2006, Baltimore, The Johns Hopkins University Press, p. 75.

${ }^{5}$ Cfr. Robert McCaughey, Stand, Columbia: A History of Columbia University in the City of New York, 1754-2004, New York, Columbia University Press, 2003, pp. 293-9.

${ }^{6}$ Otra colección importante: The Loeb Classical Library, colección bilingüe (griego-inglés, latín-inglés) que abarca escritores griegos y latinos y cuyo fin ha sido acercar a los grandes autores clásicos al mayor número de lectores. Para los especialistas, se presenta el texto original; además, se ofrece una cuidada traducción al inglés. El primer número apareció en 1911.

${ }^{7}$ Cfr. John Henry Newman, The Idea of a University. 1999, Washington, D.C., Regnery Publishing, pp. 221-240; José Morales, Teología, experiencia, educación. Estudios Newmanianos, 1999, Pamplona, Eunsa, pp. 137-150; Susan Hanssen, "Eccentric Education”, en Bradley Watson 
El esfuerzo de reforma que se realizó en 1930 en la universidad de Chicago también se preocupó por la selección de grandes libros e incluyó una intensa reflexión sobre el "método" de lectura y discusión que los debía acompañar. Eso facilitó que la obra de Robert Hutchins, Mortimer Adler, Stringfellow Barr (1897-1982) y Scott Milross Buchanan (18951968) se difundiera y obtuviera prestigio internacional con la publicación de los 54 volúmenes conocidos como The Great Books of the Western World, en $1952 .{ }^{8}$

La historia de los estudios generales en América Latina ${ }^{9}$ tiene que describir, cuando menos, las transformaciones que sufrió la universidad norteamericana durante los primeros años del siglo XX y explicar el proceso que se llevó a cabo en la Universidad de Chicago en la década de los treinta, como parte de la historia de la educación en Estados Unidos. ${ }^{10}$ Estas tareas resultan indispensables para entender el funcionamiento de muchas instituciones de educación superior en América Latina que adoptaron, por ejemplo, la organización departamental, los sistemas de autoevaluación institucional y programas de humanidades dentro de un proyecto de estudios generales. ${ }^{11}$

(ed.), The Idea of the American University, 2011, Lanham, Rowman \& Littlefield Publ. Group, pp. 67-79; y Dzuback, op. cit., pp. 14-125.

${ }^{8}$ Cfr. Elizabeth Kiss y Peter Euben, (eds.), Debating moral education. Rethinking the role of Modern University, 2010, Durham, Duke University Press, pp. 38-46.

${ }^{9}$ Una parte de la historia de los estudios generales en América latina ha sido documentada en: Jorge Rodríguez Beruff, "El papel de los estudios generales en los estudios universitarios contemporáneos", op.cit., pp. 30-35.

${ }^{10}$ Una historia de este tipo también debería analizar las fuentes y transformaciones que ha sufrido la educación norteamericana desde mediados de siglo XIX.

${ }^{11}$ Existen varios trabajos sobre los estudios generales en el ITAM. Algunos están dedicados a examinar su significado y disposición curricular. Otros exploran su origen y devenir. Resultan imprescindibles los textos de Javier Beristáin Iturbide (rector del ITAM de 1972-1991), Saber para prever, prever para actuar. Ensayos y reflexiones acerca de la educación, 2010, México, IAG; El ITAM; un esbozo de su historia, 1946-1986; Una historia de familia: La carrera de economía en el ITAM, y algunas semblanzas, particularmente las de Miguel Palacios Macedo, Antonio Carrillo Flores y Luis Astey. También se pueden encontrar valiosas orientaciones en el texto La flecha al aire. Homenaje a Javier Beristain. Ensayos sobre economía, desarrollo e innovación educativa, ITAM-CIDE-Porrúa, México, 2010; José Ramón Benito Alzaga: "Estudios Generales en el ITAM", Ponencia presentada en la Asamblea Nacional de ANFECA, julio de 1973; del mismo autor: "Universidad y Filosofia", en Estudios. Filosofia. Historia. Letras, núm. 1, otoño 1984; "Latinoamérica y la Universidad", en op. cit., núm. 26, otoño 1991; "Filosofía y Educación Superior", en Memoria de X Congreso Mundial Ordinario de Filosofía del Derecho y Filosofia Social, UNAM, vol. IV, 1981, pp. 177-188; "La Paideia Cristiana: una 
Sin embargo, una interpretación que considere a la raíz norteamericana de los estudios generales -como el único fundamento puede ser ocasión de múltiples equívocos y hacernos creer que los estudios generales en México no son más que una imitación de la educación liberal norteamericana, una transcripción de los cursos impartidos en Chicago y, en el peor de los casos, una introducción acrítica de los cánones del mundo anglosajón. Estas interpretaciones ignoran que el cultivo de las humanidades acompaña la historia de México desde el siglo XVI ${ }^{12}$ y que la selección y difusión de los grandes libros no es exclusiva de un pueblo, sino que estas iniciativas siempre corresponden a un clima cultural que comparten varias naciones e intelectuales en determinadas épocas, por lo que intentar establecer influencias directas y acríticas es imposible. ${ }^{13}$ Ese clima cultural subyace a las colecciones Oxford World's Classics (1901), Everyman's Library (1906), Harvard Classics (1909), Los Clásicos de José Vasconcelos (1921-1924) y The Great Books of the Western World (1952).

La preocupación por seleccionar y difundir los "grandes libros" como herramienta pedagógica tanto para las masas como para los estudiantes universitarios es un fenómeno que acompañó las políticas

interpretación", en Estudios. Filosofia. Historia. Letras, núm. 2, primavera 1985; y Notas sobre el sentido social de la formación humanista en el ITAM, versión digital en el portal del Departamento Académico de Estudios Generales, http://generales.itam.mx/docs/FORMACION\%20 HUMANISTA.pdf. Asimismo, conviene revisar Rodolfo Vázquez, "Un enfoque liberal de la educación”, en idem, núm. 30, otoño 1992, pp. 81-92; El Informe de la Comisión de Decisiones del Plan Integral Desarrollo (ITAM, febrero de 1969); Julia Sierra Moncayo, “¿Qué son los estudios generales? Notas y experiencias de un departamento académico del ITAM", idem, núm. 97, verano 2010, pp. 41-59; Reynaldo Sordo Cerdeño, "Historia sobre los cursos de México de Estudios Generales", en ibidem, pp. 61-69, y Carlos de la Isla Veraza, De esclavitudes y libertades. Ensayos de Ética, Educación y Política, 2006, México, ITAM-Porrúa.

${ }^{12}$ Cfr. Gabriel Méndez Plancarte, "Índice del Humanismo Mexicano". Conferencia sustentada en la Sala de Conferencias del Palacio de Bellas Artes, el 10 de enero de 1944, en Ábside, revista de cultura mexicana, VIII-I, enero-marzo, 1944, pp. 47-92, y en sobretiro separado: Gabriel Méndez Plancarte, Fundadores del humanismo mexicano, 1945, México, Boletín del Instituto Caro y Cuervo, pp. 247-72.

${ }^{13}$ La evolución de la educación en Estados Unidos no pasó inadvertida para un grupo importante de intelectuales en Hispanoamérica, quienes encontraron inspiración en muchas de sus innovaciones. No obstante, insistieron en señalar sus "efectos perjudiciales", sobre todo la excesiva especialización, el desorden curricular y la defensa de la propia "tradición intelectual". Véase Pedro Henríquez Ureña, "La cultura y los peligros de la especialidad", en La Unión Hispanoamericana, año V, núm. 40, 1920, pp. 28-30. 
democratizadoras que se experimentaban en algunos países europeos y americanos durante los primeros años del siglo XX. Se requería de una nueva educación pública, al alcance de todos, con el objetivo de ofrecer al ciudadano una formación intelectual, moral y estética, que le permitiera una participación crítica y responsable al servicio de proyectos nacionalistas de unidad cultural. ${ }^{14}$

Además, la publicación de los clásicos no constituye por sí misma una meta, sino que debe vincularse a una concepción de lo humano, a un proyecto educativo de largo alcance y a un compromiso de transformación y responsabilidad sociales. ${ }^{15} \mathrm{Al}$ respecto, es interesante lo que declara el economista Richard Levin (1947-), quien ocupó el cargo de rector de la Universidad de Yale por 20 años, sobre las ambiciosas agendas actuales de China y la India en la educación universitaria, que parecen inspirarse, al menos para unos cuantos, en el sistema tutorial de Oxford y Cambridge, y que en Estados Unidos ha tenido equivalente en el "seminario interactivo":

La Universidad de Beijing abrió en 2001 el Programa Yuanpei para alumnos destacados, un programa piloto que introduce a un grupo selecto de los estudiantes chinos mejor dotados en un ambiente de estudios humanísticos. Estos estudiantes viven juntos y exploran una amplia variedad de asignaturas durante dos años, antes de elegir una especialidad para sus estudios. ${ }^{16}$

${ }^{14}$ Cfr. Eric Hobsbawm, La era del Imperio, 1848-1875, 1998, Buenos Aires, Crítica Grijalbo-Mondadori, p. 285; Robert Hutchins, La Universidad de Utopía, 1968, Buenos Aires, Eudeba, pp. 9-32.

${ }^{15}$ En los últimos años, se han extendido distintas propuestas de reforma a la vida universitaria en prácticamente todo el mundo. En muchas de ellas, el estudio de las humanidades se relega en beneficio de aprendizajes directamente vinculados con la actividad económica. El trabajo de Martha Nussbaum reflexiona sobre estas circunstancias y hace una defensa de la educación liberal, según la cual la formación de los estudiantes universitarios coincide con las propuestas de la cultura clásica, que no son otras que aquellas que conducen al cultivo de la humanidad. Martha Nussbaum, Sin fines de lucro. Por qué la democracia necesita de las humanidades, 2010, Madrid-Bs. As., Katz Editores, serie Discusiones, pp. 199; El cultivo de la humanidad. Una defensa clásica de la reforma en la educación liberal, 2005, Barcelona, Paidós, pp. 338; y Rafael González Díaz, "Evaluación del enfoque educativo imperante basado en el desarrollo de competencias a la luz de la educación mayéutica", en Estudios. Filosofia. Historia. Letras, núm. 97, Verano 2011, pp. 73-102.

${ }^{16}$ Richard Levin, "El mejor de la clase. El ascenso de las universidades asiáticas", en Foreign Affairs Latinoamérica, vol. 10, núm. 3, 2010, pp. 88-9. 
Parece que, toda vez que la Universidad quiere pensar en sí misma para renovarse, vuelve a sus orígenes. De nuevo, el método clásico de lectio, repetitio y disputatio como esencia, cimiento y base de la vida universitaria; origen de la ciencia moderna como exigencia natural del cultivo de las humanidades. ${ }^{17} \mathrm{Sin}$ duda, resultan significativas las coincidencias entre los rectores de Chicago, R. M. Hutchins (1899-1977), Harvard, C. W. Eliot (1834-1926), el ITAM, J. Beristain (1944-2009) y la Universidad Nacional de México - hoy UNAM- J. Vasconcelos (1882-1959). Hicieron grandes obras porque sus proyectos fueron a la raíz; construyeron grandes instituciones porque se remitieron a la fuente de donde proceden el vigor y el rigor para la vida universitaria. Descubrieron como algo inestimable el método, la necesidad de la libertad de cátedra, la lectura y el debate de las ideas. Entendieron que la buena educación, más allá de los conocimientos científicos y técnicos, se propone convertir a cada estudiante en sujeto consciente y capaz de orientarse, al correr de los años, en la búsqueda del sentido de las cosas y de la vida, transformando la información en conocimiento y el conocimiento en sabiduría, aprendiendo con ello a vivir. ${ }^{18}$

Además, todos estos rectores se caracterizaron por asumir su responsabilidad siendo muy jóvenes: Robert Hutchins (Chicago) a los 1430 años; Charles W. Elliot (Harvard) a los 35; Javier Beristain (ITAM) a los 33 años y José Vasconcelos (UNM) a los 38; los cuatro impulsaron procesos de reforma en su universidad y la fundamentaron en el cultivo de las humanidades. Se preocuparon por acudir a las fuentes del pensamiento occidental y su legado continúa hasta nuestros días. Estas concepciones llevaron a Josep Pieper (1904-1997) a reconocer con admiración:

Hay que decir aquí unas palabras, por ejemplo, acerca del experimento de los "grandes libros" emprendido hace años en los centros académicos de América, con lo que se alude a los libros que representan el "legado" desde Homero, pasando por Platón, Aristóteles, Virgilio, Plotino,

${ }^{17}$ Cfr. Augusto Iyanga Pendi, Historia de la Universidad en Europa, 2000, Valencia, Universitat de València.

${ }^{18}$ Cfr. Pablo Latapí Sarre, Una buena educación: Reflexiones sobre la calidad, 2008, México, Universidad de Colima, p. 20. 
Agustín, Tomás, Dante, hasta Shakespeare, Kant, Hegel, Goethe, Darwin, Dostoiewski y Sigmund Freud. Este experimento, llevado a cabo con la seriedad de una asombrosa imparcialidad, sobre el que con razón se puede polemizar en aspectos particulares, ha nacido de la preocupación y del firme propósito de que el propio tesoro recibido esté o pueda estar a disposición del Nuevo Continente, pudiendo de esta manera ser enseñado y aprendido. ${ }^{19}$

En Estados Unidos, como lo ha advertido el doctor José Barba, ${ }^{20}$ la publicación de los grandes libros está vinculada con la obra de Charles William Eliot (1834-1926) ${ }^{21}$ en la Universidad de Harvard. Nombrado presidente de la Universidad a la edad de 35 años llegó a considerársele el artífice de una de las transformaciones más radicales y profundas que experimentó esa universidad, entre 1896-1909. ${ }^{22}$ Como presidente de la misma, se encargó de seleccionar y publicar una colección de 51 volúmenes conocida como los Harvard Classics, editados desde 1909. El propósito de la obra, según Charles William Eliot:

Mi propósito en la selección de los Harvard Classics era proporcionar a un lector atento y persistente los materiales literarios de los cuales pudiera obtener una imagen fiel del progreso del hombre, observando, registrando, inventando e imaginando, desde los primeros tiempos históricos hasta el fin del siglo XIX. Dentro de los límites de cincuenta volúmenes,

${ }^{19}$ Josef Pieper, Filosofía medieval y mundo moderno. Escolástica, figuras y problemas de la filosofía medieval, 1973, Madrid, Rialp, pp.184-185. En este mismo apartado, Pieper profundiza en una nota: "La serie de los Great Books of the Western World, aparecidos en la editorial de la Encyclopaedia Britannica en 1952, editados por R. M. Hutchins (en un total de 54 tomos) son totalmente escolásticos y, según mi parecer, enfocados de una manera extraordinariamente pedagógica mediante dos amplios tomos introductorios titulados The Great ideas. A Synopticon for Great Books of the Western World".

${ }^{20}$ Durante muchos años, catedrático del Departamento Académico de Estudios Generales del ITAM, y a quien agradezco la orientación al respecto.

${ }^{21} \mathrm{Cfr}$. W. Charles Eliot, "Inaugural Address as President of Harvard College, October 19, 1869", en W. Allan Neilson, Charles W. Eliot, The Man and his Beliefs, 1926, New York, Harper \& Bros, vol. 1., pp. 20; W. Charles Eliot, The Durable Satisfactions of Life, 2004, Whitefish, MT, Kessinger Publishing, pp. 11-56; y Kathlee Wilder, Joan, Charles William Eliot and American Educational Reform 1909-1926, 1970, Madison, WI, University of Wisconsin, pp. 87.

${ }^{22}$ Cfr. Samuel Eliot Morison, Three Centuries of Harvard, 1936, Cambridge, MA, Harvard University Press, pp. 323-484. 
que contienen 22,000 páginas, iba a proporcionar los medios para obtener un conocimiento tal de la literatura antigua y moderna, como parece esencial a la idea de un hombre culto del siglo XX. ${ }^{23}$

La obra también fue conocida como Dr. Eliot's Five Foot Shelf, por una de sus declaraciones, según la cual, los elementos de una educación liberal se alcanzaban destinando 15 minutos diarios a la lectura de una colección de libros que podían caber en un anaquel de cinco pies, -aunque en un principio haya medido sólo tres:

Antes de que el plan de lectura que representan los Harvard Classics hubiera tomado forma definitiva, había declarado en público, más de una vez, que en mi opinión, una estantería de cinco pies - originalmente de trespodría contener los libros suficientes como para acceder a un buen substituto de educación liberal a cualquiera que los leyera con dedicación, aunque sólo pudiera destinar quince minutos al día para su lectura. ${ }^{24}$

Este proyecto editorial contó con el respaldo y la sagacidad empresarial de Peter F. Collier (1849-1909) y de su hijo Robert Joseph (1876-1918), editores de los Harvard Classics, colección exhaustiva que fue tan redituable económicamente gracias a sus agresivas estrategias publicitarias. ${ }^{25}$ Se estima que en veinte años vendieron cerca de 350 mil colecciones. ${ }^{26}$ Sin embargo, los Harvard Classics no pueden considerarse los pioneros y precursores en la publicación masiva de clásicos. Antes que se iniciara su publicación, en Inglaterra existían ya otras

${ }^{23}$ W. Charles Eliot, Fifteen minutes a day: the reading guide, 1930, vol. 52 de Harvard Classics, Collier \& Son Company, p. 7. La traducción es mía.

${ }^{24}$ Ibidem.

${ }^{25} \mathrm{Al}$ respecto es interesante observar que en México en 1959 apareció una colección bajo el nombre de "Sepan Cuántos...", bautizada así por el ilustre Alfonso Reyes, dedicada a la publicación de las obras clásicas de todos los tiempos, bajo el precepto: "la cultura al alcance de todos", en: https://www.porrua.mx/conocenos.php. [12 de junio de 2013].

${ }^{26}$ Vale la pena señalar que, según Alex Beam, las transformaciones realizadas por Charles W. Eliot en la Universidad de Harvard fueron conocidas por Robert Hutchins y que Mortimer Adler tuvo acceso a la selección de Platón de los Harvard Classics; cada uno fue crítico de la selección y de los modelos de operación de Eliot. Recomiendo Alex Beam, A Great Idea at the time. The Rise, Fall and Curious Afterlife of the Great Books, 2008, New York, Public Affairs, pp. 1-19. 
influyentes colecciones como los Oxford's World's Classics (1901) y los Everyman's Library (1906). Las rigurosas investigaciones de Richard D. Altick ${ }^{27}$ y Thomas F. Bonnell ${ }^{28}$ sobre las reimpresiones de los clásicos ingleses en el siglo XVIII y XIX ${ }^{29}$ reconocen que la nueva era de accesibilidad a los clásicos, en el siglo XX, comenzó formalmente en 1906, con la colección Everyman's Library, de Joseph Malaby Dent (1849-1926). Estos libros revolucionaron la reimpresión de los clásicos por su novedoso formato y sus originales presentaciones..$^{30}$ Aunque Dent tuvo dificultades con los derechos de autor en el proceso inicial de selección de las obras, la colección adquirió prestigio y fue convirtiéndose en una autoridad indiscutible en la esfera literaria. ${ }^{31}$ Los libros tenían un tamaño de bolsillo y usaron colores para identificar cada una de las series. Posteriormente, incluyeron el delfín y el ancla como colofón o marca de imprenta, el famoso logotipo usado por Aldus Manutius (1449-1515) para su casa editorial. El formato y la cuidadosa tipografía de las tapas, sobrecubiertas y solapas distinguieron a estos libros y les otorgaron calidad y estima. ${ }^{32}$

${ }^{27}$ Cfr. Richard Altick, The English Common Reader: A Social History of the Mass Reading Public, 1800-1900, Chicago, University of Chicago Press, 1957; To be in England: An American Literary Man's Personal View, 1969, New York, Norton \& Company, p. 294; y "From Aldine to Everyman: Cheap Reprint Series of the English Classics, 1830-1906", en Studies in Bibliography, núm. 11, 1958, pp. 3-24.

${ }^{28}$ Cfr. Thomas Bonnell, The Most Disreputable Trade. Publishing the Classics of English Poetry. 1765-1810, 2008, Oxford-New York, Oxford University Press., pp. 8; y "Bookselling and Canon-Making: The Trade Rivalry over the English Poets, 1776-1783", en Studies in Eighteenth-Century Culture, núm. 19, 1989, pp. 55.

${ }^{29}$ Estas investigaciones coinciden en que la era victoriana despertó un profundo interés en América y propició un ambiente oportuno para la publicación de una miríada de clásicos en ediciones baratas. Bonnell también ha explorado la conexión entre los imperativos del mercado, los derechos de autor y su comercialización con la creación del "cannon" inglés, especialmente las colecciones de clásicos en Inglaterra, que aparecieron $c a$. 1774, con las modificaciones a los derechos de autor por el caso Becket vs. Donaldson.

${ }^{30}$ Joseph M. Dent ya había publicado los Temple Classics y 40 volúmenes de Temple Shakespeare.

${ }^{31}$ Para conocer una lista pormenorizada de los catálogos y obras que fueron publicadas por J. M. Dent, entre ellos la colección Everyman's Library, se pueda revisar: Terry Seymour, $A$ printing history of Everyman's Library 1906-1982, 2011, Bloomington, Ind. AuthorHouse, pp. 19-28; y A guide to collecting Everyman's Library, 2005, Bloominton, Ind. AuthorHouse, pp. 380

${ }^{32}$ Cfr. Rebecca Rego Barry, "The Neo-Classics. (Re) Publishing the 'Great Books' in the United States in the 1990s", en Book History, 6, 2003, pp. 251-75. 
Sostener que los estudios generales son fruto exclusivo de proyectos europeos y estadounidenses adolece de rigor histórico; ignora una historia de las humanidades y los estudios generales en México, con otras raíces y cuyos antecedentes remotos son igualmente robustos e incluso más significativos, dado que están vinculados con los proyectos, particularmente originales, del humanismo mexicano del siglo XX. Entre ellos, destacan el Ateneo de la Juventud, el grupo de los Siete Sabios y la denominada Generación de 1915. Merecen una mención especial la influencia de Miguel Palacios Macedo (1898-1990), Daniel Cosío Villegas (1898-1976) y Manuel Gómez Morín (1897-1972). Estas iniciativas constituyen una protohistoria de los estudios generales en México y explican el interés por la adopción y desarrollo del programa que se realizaba en la Universidad de Chicago. Años después, Daniel Cosío Villegas recomendó a la fundadora de la Facultad de Economía de la Universidad de Nuevo León, Consuelo Meyer L'Epée, la adaptación de un curso que se impartía en la Universidad de Columbia. Dice Consuelo Meyer (1918-2010):

Se introdujo por sugestión de Don Daniel Cosío Villegas un curso de Civilización Contemporánea que se daba en la Universidad de Columbia de EUA [...] Entonces recurrí a profesores mexicanos, un pequeño grupo de intelectuales encabezado por el profesor Arturo Cantú, quien había estudiado filosofía aquí en México, para que ellos formaran un comité editorial de los materiales de ese curso que duraría dos años, que iba a sustituir a multitud de cursos introductorios en sociología, economía y otras ciencias; ese curso consistía en estudios y selecciones tomadas de la obra de más de 70 autores de nombre universal, desde la edad clásica griega hasta mediados del siglo XX. [...] Yo pensé que ese curso tenía un gran porvenir, lo mandé a diversas universidades de América Latina, con el fin de que si se interesaban, lo adoptaran y aprovecharan el trabajo de este grupo de jóvenes mexicanos, entre los que además de Arturo Cantú, formaban parte el licenciado Lucas de la Garza, que hizo aportaciones muy importantes a ese curso; los hice venir a México a inspeccionar las reservas de la librería más grande de la ciudad, que entonces era Editorial Porrúa, para que seleccionaran toda la bibliografía que les pareciera útil y conveniente para después [...] Puse especial 
hincapié en matemáticas y estadística, y este curso que era hijo de mi alma de Civilización Contemporánea. ${ }^{33}$

La sugerencia de Daniel Cosío Villegas tiene su origen en el ambiente intelectual en el que fue formado y en el proyecto cultural del que participó, junto con otros miembros de su generación, casi tres décadas antes del movimiento de reforma universitaria en Estados Unidos. E1 estudio de esta etapa es muy sugerente. Por ejemplo, la reacción frente a la estrechez positivista reanimó el cultivo de las humanidades en la Universidad de Columbia (1921) y las transformaciones curriculares en Chicago (1930); dicha reacción fue sentida mucho tiempo antes por los miembros del Ateneo de la Juventud (1907) y se tradujo en la creación de la Sociedad de Conferencias y en el surgimiento de los cenáculos en los que se dialogaba en torno a los grandes obras. Otro ejemplo estimulante: diez años antes de que Robert Hutchins hubiera iniciado su proyecto de reforma en la Universidad de Chicago, y treinta y dos años antes de que se publicaran los Great Books of the Western World, ${ }^{34} \mathrm{el}$

${ }^{33}$ Consuelo Meyer, "Plática con la Srita. Consuelo Meyer", Contrapunto, núm. 2, 2007, pp. 23-24; y "Prólogo. Evolución de la Civilización Contemporánea”, La herencia Clásica, 1963, México, Comité Editorial del Curso de Evolución de la Civilización Contemporánea, Facultad de Economía, Universidad de Nuevo León, pp. ix-xx. En el ITAM, estos cursos se organizaron en un conjunto de asignaturas comunes que son: Ideas e Instituciones Políticas y Sociales, Problemas de la Civilización Contemporánea, Historia Socio-Política de México y Problemas de la Realidad Mexicana Contemporánea. En el caso de los cursos de Ideas e Instituciones Políticas y Sociales, "la parte medular está constituida por textos de pensadores que han contribuido en forma preponderante a la creación de una cosmovisión o la integración de la misma, partiendo de un método intelectual o algo equivalente de manera que puedan así contextualizarse sus ideas políticosociales.” Sus contenidos y volúmenes: Introducción al análisis histórico, Grecia, Sófocles, Platón, Aristóteles, Roma, Séneca, San Agustín, Edad Media, Santo Tomás, Dante, Los cambios, Antiguo Régimen, Descartes, Spinoza, Hobbes, Locke, Hume, Ilustración, Rousseau, Kant, Romanticismo, Hegel, Capitalismo y Revolución Social, Comte, John, Stuart Mill, Karl Marx, La era del imperialismo, Nietzsche, Freud, Bergson, El siglo XX, Wittgenstein y Heidegger. Cfr. http://generales. itam.mx/contenido/materias.html\# [30 de mayo de 2013].

${ }^{34}$ Robert Hutchins y Adler Mortimer, Great Books of the Western World, 1952, Chicago, Encyclopedia Britannica. 54 volúmenes, con el siguiente contenido: 1. The great conversation, by R.M. Hutchins. 2-3. The great ideas. 4. The Iliad of Homer. The Odyssey. 5. Aeschylus. Sophocles. Euripides. Aristophanes. 6. Herodotus. Thucydides. 7. Plato. 8-9. Aristotle. 10. Hippocrates. Galen. 11. Euclid. Archimedes. Appollonius of Perga. Nicomachus. 12. Lucretius. Epictetus. Marcus Aurelius. 13. Virgil. 14. Plutarch. 15. Tacitus. 16. Ptolemy. Copernicus. Kepler. 17. Plotinus. 18. Augustine. 19-20. Thomas Aquinas. 21. Dante. 22. Chaucer. 23. Machiavelli. Hobbes. 24. Rabelais. 25. Montaigne. 26-27. Shakespeare. 28. Gilbert. Galileo. Harvey. 
rector de la Universidad de México, José Vasconcelos, presentó el 22 de octubre de 1920, una Iniciativa de Ley para la Creación de una Secretaría de Educación Pública Federal, en la que se utilizó la expresión "libros grandes" en estos términos:

La luz, la fe, la acción, el gran anhelo de bien que conmueve a esta sociedad contemporánea, apenas si se define en los libros; en los libros de nuestros contemporáneos y en los libros grandes y generosos del pasado: por eso un Ministerio de Educación que se limitara a fundar escuelas, será como un arquitecto que se conformase con construir las celdas sin pensar en las almenas, sin abrir las ventanas, sin elevar las torres de un vasto edificio. En las escuelas se nos educa para que aprendamos a distinguir y a juzgar, para que sepamos apreciar qué es lo que vale entre toda la multiplicidad de los esfuerzos humanos; pero sólo en el vehículo generoso de los libros encontramos el tesoro de la cultura humana. La escuela nos alecciona en los métodos y en seguida los libros nos dan las ideas, la riqueza, la prodigalidad entera de la conciencia. He aquí por qué el Departamento de Bibliotecas no debe ser visto como una novedad curiosa o como un lujo superfluo. ${ }^{35}$

Las cursivas y la acentuación del color de la tipografía tienen la finalidad de destacar que Vasconcelos usó la expresión libros grandes desde el comienzo de su ambicioso proyecto editorial, en 1920. La frase libros grandes podría traducirse al idioma inglés como Great Books, la misma expresión que coincidentemente se usó, años después, en la Universidad de Chicago.

29. Cervantes. 30. Francis Bacon. 31. Descartes. Spinoza. 32. John Milton. 33. Pascal. 34. Newton. Huygens. 35. Locke. Berkeley. Hume. 36. Swift. Sterne. 37. Henry Fielding. 38. Montesquieu. Rousseau. 39. Adam Smith. 40-41. Gibbon. 42. Kant. 43. American state papers. The Federalist. J.S. Mill. 44. Boswell. 45. Lavoisier. Fourier. Faraday. 46. Hegel. 47. Goethe. 48. Melville. 49. Darwin. 50. Marx. 51. Tolstoy. 52. Dostoevsky. 53. William James. 54. Freud.

${ }^{35}$ Proyecto de ley para la creación de una Secretaría de Educación Pública Federal presentado por el Ejecutivo de la Unión a la XXIX Legislatura, 1920, México, Universidad Nacional, Imprenta Franco-Mexicana; y Claude Fell, José Vasconcelos, Los años del Águila, 1989, México, UNAM, p. 21. 


\section{Los "grandes libros" y el Ateneo de la Juventud}

En el México pre-revolucionario, el positivismo imperaba de manera legal en la Escuela Nacional Preparatoria y en las demás escuelas profesionales dependientes del Estado. Si bien ya no tenía la fuerza original del proyecto de Gabino Barreda (1819-1881), discípulo de Augusto Comte (1798-1857), seguía vigente como el único criterio que regía la política educativa y las manifestaciones de la vida intelectual en México; además, fundamentaba la ideología del grupo de Los científicos que conducían la política económica del Porfiriato. ${ }^{36}$ Dice Leopoldo Zea (1912-2004):

La nueva generación se considerará a sí misma como la destinada, por su capacidad, para guiar y orientar al país. Sus métodos son seguros, perfectos y precisos. Son los métodos de la ciencia, los que aprendieron en las escuelas reformadas por Gabino Barreda. Estos métodos -dicenserán aplicados a la solución de todos los problemas de México, incluyendo los políticos. En 1881 hablan ya de la escuela científica política de México. En 1886 varios de sus miembros entran a la Cámara de Diputados. Algunos de ellos serán en el futuro figuras destacadas del régimen de Porfirio Díaz: Justo Sierra, Pablo Macedo, Rosendo Pineda, Francisco Bulnes y otros. Todos pondrán, en conjunto, su sello a la época que lleva el nombre de porfirismo. Empezaba la era de los científicos. ${ }^{37}$

Todas las expresiones intelectuales que se alejaban de los postulados de Augusto Comte (1789-1857), John Stuart Mill (1806-1873) y Herbert Spencer (1820-1903) eran excluidas de facto por su falta de correspondencia con el rígido canon que se había instaurado. ${ }^{38}$ Sin embargo, a finales del siglo XIX y comienzos del XX, un grupo de jóvenes, sin desligarse de manera radical del régimen intelectual y político en el que se habían formado, cuestionaron los resultados de tal tradición educativa

${ }^{36}$ Cfr. Antonio Caso, México (apuntamientos de cultura patria), 1943, México, Imprenta universitaria, p. 85.

${ }^{37}$ Leopoldo Zea, "El positivismo", en Estudios de la Filosofía en México, 1963, México, UNAM, pp. 243.

${ }^{38}$ Cfr. Alfonso Reyes, Pasado inmediato, 2007, México, FCE-Cátedra Alfonso Reyes del Tecnológico de Monterrey, pp. 133-73. 
que ya consideraban estéril. La crítica al positivismo se inició desde que Justo Sierra (1848-1912) rechazó su contenido doctrinario en el discurso de homenaje a Gabino Barreda (1819-1881) en 1874. ${ }^{39}$ A principios de 1906, un grupo de jóvenes escritores y artistas fundó la revista Savia Moderna ${ }^{40}$ que duró poco, pero significó el abandono de la influencia francesa en la literatura y del positivismo en filosofía. ${ }^{41}$ El mismo Alfonso Reyes (1889-1959), en Pasado Inmediato, describe la herencia recibida en esas escuelas y la insuficiencia que el sistema positivista generaba en las genuinas inquietudes del estudiantado:

Se prescindía de las humanidades, y aún no se llegaba a la enseñanza técnica para el pueblo: ni estábamos en el Olimpo, ni estábamos en la tierra, sino colgados en la cesta, como el Sócrates de Aristófanes. Ayuna de humanidades, la juventud perdía el sabor de las tradiciones, y sin quererlo se iba descastando insensiblemente [...] La herencia de Barreda se fue secando en los mecanismos del método. Hicieron de la matemática la Suma del saber humano. Al lenguaje de los algoritmos sacrificaron poco a poco la historia natural y cuanto Rickert llamaría la ciencia natural, y en fin las verdaderas humanidades. ${ }^{42}$

En ese legendario grupo de intelectuales que formaron parte del Ateneo intervinieron figuras tan importantes como Pedro Henríquez Ureña (1884-1946), Alfonso Reyes (1889-1959), José Vasconcelos (1882-1959), Antonio Caso (1883-1946) y Julio Torri (1889-1970), entre otros. El grupo estuvo integrado por escritores, músicos, ingenieros, abo-

${ }^{39} \mathrm{Cfr}$. Justo Sierra, "Una fiesta íntima (Homenaje al doctor Gabino Barreda)", en La Tribuna, 26 de febrero de 1878. En esta intervención, Justo Sierra mantiene una aceptación crítica del positivismo, junto con otras doctrinas; incluso defiende la necesidad de cultivar la historia de la filosofía.

${ }^{40}$ Cfr. Alfonso García Morales, El Ateneo de México, (1906-1914): orígenes de la cultura mexicana contemporánea, 1992, Madrid, CSIC, pp. 41-9.

${ }^{41} C f r$. Fernando Salmerón, "Los filósofos mexicanos del siglo XX", en Estudios de historia de la filosofia en México, 1963, México, UnAM, pp. 269-319; y Alfonso García Morales, El Ateneo de México (1906-1914), op. cit., pp. 69-106.

${ }^{42}$ Alfonso Reyes, Pasado inmediato, op. cit., pp. 151. Augusto Comte, en el Curso de Filosofia Positiva, lección XVIII, publicado en París en 1830, dice sobre las matemáticas: "Por tanto, es la ciencia matemática la que debe constituir el punto de partida de toda educación científica racional, sea general, sea especial, lo cual explica el uso universal que se ha establecido desde hace largo tiempo a este respecto, de una manera empírica; aunque primitivamente no tuviera más causa que la mayor ancianidad relativa de la ciencia matemática”. Cursivas mías. 
gados, arqueólogos, filósofos, arquitectos, representaron el cambio generacional que transformó la educación y la cultura en México durante el siglo $\mathrm{XX} .{ }^{43}$ Aunque este movimiento de renovación cultural no alcanzó homogeneidad política, tiene características comunes:

Los rasgos más característicos del grupo del Ateneo se precisan en contraposición con el positivismo de sus maestros. La nueva generación opuso: contra el darwinismo social, el concepto de libre albedrío, la fuerza del sentimiento de responsabilidad humana que debe presidir la conducta individual y social; contra el fetichismo de la ciencia, la investigación de los "primeros principios"; contra la conformidad burguesa de la supervivencia de los aptos, la jubilosa inconformidad cristiana de la vida integrada por ricos y miserables, por cultos e incultos, y por soberbios y rebeldes. Pensó, con razón, que era preciso acercar otra vez el espíritu a las fuentes puras de la filosofía y de las humanidades, y que era menester generalizar estas ideas, no sólo entre la clase ilustrada sino también entre el pueblo. ${ }^{44}$

Los jóvenes del Ateneo se dedicaron, extracurricularmente, a leer y discutir, en pequeños grupos, una serie de autores que la "filosofía oficial” y los planes de estudios tenían proscritos en las aulas. Eso despertó en ellos un vivo sentido de libertad de cátedra y de pensamiento, como enfatiza Pedro Henríquez Ureña: "Sentíamos la opresión intelectual junto con la opresión política y económica de que ya se daba cuenta gran parte del país. Veíamos que la filosofía oficial era demasiado sistemática, demasiado definitiva para no equivocarse". ${ }^{45}$

${ }^{43}$ La bibliografía sobre el Ateneo es muy abundante; destaco: Álvaro Matute Aguirre, El Ateneo de México, 1999, México, FCE; "El Ateneo de la juventud: grupo, asociación civil, generación", en Mascarones, Boletín del Centro de Enseñanza para los Extranjeros, núm. 2, primavera, 1983, p. 16-27; Juan Hernández Luna, "Prólogo. El Ateneo de la Juventud", en Antonio Caso, et al., Conferencias del Ateneo de la Juventud, 2000, México, UNAM, pp. 9-23; Fernando Curiel Defossé, La revuelta: interpretación del Ateneo de la juventud (1906-1929), 1998, México, UNAM; Elementos para un esquema generacional aplicable a cien años (aprox.) de literatura patria, 2001, México, UNAM; y Ateneo de la juventud (A-Z), 2001, México, UNAM.

${ }^{44}$ Vicente Lombardo Toledano, "El sentido humanista de la revolución mexicana. Conferencias del Ateneo de la Juventud", en Revista Universidad de México, t. I, núm. 2, 1962, p. 173.

${ }^{45}$ Pedro Henríquez Ureña, "La revolución y la cultura en México”, en Ensayos, 1998, Madrid, ALLCA XX, edición crítica de José Luis Abellán y Ana María Barrenechea, pp. 256. 
Por eso admiraban a todos aquellos profesores que les permitieron nutrirse de nuevas corrientes de pensamiento. ${ }^{46}$ Dedicaron especial atención a la lectura cuidadosa de la obra de Platón, Arthur Schopenhauer, Kant, Bergson, William James, Poincaré, Nietzsche, Schiller, Gotthold Lessing, Hegel y Benedetto Croce, entre otros. En sus memorias, se describe lo beneficioso que resultó este ejercicio. Para ello, fundaron "pequeños cenáculos" en donde se leían y comentaban a los autores que iban conociendo. ${ }^{47}$ Se convirtieron en un espacio privilegiado para el diálogo y la crítica colectiva. En algunos casos, se llegó a practicar la lectura en voz alta de una obra clásica. Por ejemplo, José Vasconcelos describe lo siguiente:

En la casa de Alfonso Reyes, circundados de libros y estampas célebres, disparatábamos sobre todos los temas del mundo. Preocupados, sin embargo, de poner en orden nuestro divagar y buscando bases distintas de las comtianas, emprendíamos la lectura comentada de Kant. No logramos pasar de la Crítica de la razón, pero leíamos ésta, párrafo a párrafo, deteniéndonos a veces en un renglón. Luego, como descanso y recreo de la tarea formal, leíamos colectivamente El banquete o el Fedro. Llevé yo por primera vez a estas sesiones un doble volumen de diálogos de Yajnavalki, y sermones de Buda en la edición inglesa de Max Müller, por entonces reciente. ${ }^{48}$

En segundo lugar, estos jóvenes se convencieron de la urgencia de un trabajo intelectual, serio, riguroso y esforzado. Ni la filosofía, ni el arte, ni las letras son mero pasatiempo, sino una profesión que exige disciplina y trabajo. Tenían la convicción de que las "cosas deben

${ }^{46}$ Alfonso Reyes reconoce que muchas de sus inquietudes fueron animadas y secundadas por hombres ilustres y cultos del Porfiriato: Pablo Macedo, José María Vigil, Enrique González Martínez, Luis Urbina y, sobre todo, el primer Secretario de Instrucción Pública y Bellas Artes, Justo Sierra: “Es el primero que cita en México a D'Annunzio y a Nietzsche. En sus discursos hay un material abundante de estudios y meditaciones, y el mejor comentario acaso sobre sus empeños de educador [...] Justo Sierra se multiplicó en las escuelas, como si, partido en mil pedazos, hubiera querido a través de ellas darse en comunión a las generaciones futuras", Alfonso Reyes, "Justo Sierra y la historia patria" en México, 2007, México, FCE-Cátedra Alfonso Reyes del Instituto Tecnológico de Monterrey, pp. 178-80.

${ }^{47}$ Cfr. Juan Hernández Luna, op. cit., pp. 8-13; y José Joaquín Blanco, Se llamaba Vasconcelos. Una evocación crítica, 2013, México, FCE, pp. 105.

${ }^{48}$ José Vasconcelos, Ulises criollo, México, 1935, Ediciones Botas, pp. 311-2. 
saberse bien y aprenderse de primera mano, hasta donde sea posible". ${ }^{49}$ Estaban concientes de que la excelencia es resultado de un trabajo laborioso y difícil de dominar, en el que se debe invertir mucho tiempo. Sin este sacrificio y rigor, "ningún producto de la inteligencia es duradero". ${ }^{50}$ Es decir, todo ejercicio intelectual, necesita de completa entrega y ahínco. ${ }^{51}$ Abunda el dominicano Pedro Henríquez Ureña:

Espíritu capaz de abarcar con visión personal e intensa los conceptos del mundo, de la vida y de la sociedad, y de analizar con fina percepción de detalles los curiosos paralelismos de la evolución histórica y las variadas evoluciones que en el arte determina el inasible elemento individual. $^{52}$

En tercer lugar, el grupo se caracterizó por el estudio de la cultura griega, la literatura inglesa, alemana y española. ${ }^{53}$ La lectura de los griegos fue una de sus pasiones. Sin embargo, nunca se le concibió de modo excluyente. De nuevo Henríquez Ureña, uno de los que más influyó en el grupo:

Cultura fundada en la tradición clásica no puede amar la estrechez [...] El pueblo griego introduce en el mundo la inquietud del progreso. Cuando descubre que el hombre puede individualmente ser mejor de lo que es y socialmente vivir mejor de cómo vive, no descansa para averiguar el secreto de toda mejora, de toda perfección. Juzga y compara; busca y experimenta sin tregua: no le arredra la necesidad de tocar a la religión y a la leyenda, a la fábrica social y a los sistemas políticos. Mira hacia atrás, y crea la historia; mira al futuro, y crea las utopías, las cuales, no lo olvidemos, pedían su realización al esfuerzo humano. Es el pueblo que inventa la discusión; que inventa la crítica. Funda el pensamiento libre y la investigación sistemática. ${ }^{54}$

${ }^{49}$ Martin Luis Guzmán, “Alfonso Reyes y las letras mexicanas”, en Antonio Caso, et al. Conferencias del Ateneo de la Juventud, op. cit., p. 486.

${ }^{50} \mathrm{Ibid}$.

${ }^{51}$ El significado del rigor intelectual y la búsqueda de la excelencia fueron transmitidos a la generación de 1915, quienes los divulgaron en las instituciones que fundaron.

${ }^{52}$ Pedro Henríquez Ureña, Horas de estudio, 1910, París, Ollendorf, p. 292.

${ }^{53}$ Alfonso Reyes, Pasado inmediato, op.cit., pp. 133-73.

${ }^{54}$ Pedro Henríquez Ureña, "La cultura de las humanidades", en Antonio Caso, et al., Conferencias del Ateneo de la Juventud, op. cit., pp. 175. 
Finalmente, los miembros del Ateneo de la Juventud mostraron una preocupación en torno a la identidad mexicana e hispanoamericana, que se expresó en una abundante producción literaria. ${ }^{55}$ Detrás de esa visión universalista de la cultura se escondía la confianza de que ese cultivo de las humanidades les ofrecía el sutil influjo espiritual para pensar su propia cultura.

La imitación europea parecía más elegante que la investigación de las realidades más cercanas. Sólo algunos conservadores, desterrados de la enseñanza oficial, se comunicaban celosamente, de padres a hijos, la reseña secreta de la cultura mexicana; y así, paradójicamente, estos vástagos de imperialistas que escondían entre sus reliquias familiares alguna librea de la efímera y suspirada Corte, hacían de pronto figura de depositarios y guardianes de los tesoros patrios. ${ }^{56}$

Los miembros de Ateneo fueron los precursores intelectuales de la revolución, pero no sus directores políticos: eran demasiado jóvenes en 1910 y carecían de la influencia necesaria para que sus proyectos involucraran a numerosos sectores de la población. No obstante, su exigencia de libertad intelectual contribuyó sustantivamente en el movimiento 26 maderista y en las generaciones siguientes.

Después de los años de violencia revolucionaria, el anhelo que las nuevas generaciones tenían de transformar al país encontró las condiciones sociales, económicas y políticas para la fundación de las instituciones que necesitaba la nación. Vasconcelos, uno de los miembros más distinguidos de su generación, representa la unión de la vida intelectual con la acción política. Su figura es un puente emblemático entre el proyecto del Ateneo de la Juventud y las obras que realizaron los miembros de la Generación de 1915. Su obra educativa y cultural constituye hasta el presente uno de los pilares de la identidad nacional. Afirma Eduardo García Maynez, primer director general del Instituto Tecnológico de México —posteriormente ITAM—, de 1946 a 1951: “José Vasconcelos, abogado y

${ }^{55}$ Cfr. Mónica Chávez González, "Antonio Caso y los paradigmas de la nación mexicana”, en Cuiculco, enero-abril, año/vol. 11, núm. 30, 2004, p. 7.

${ }^{56}$ Alfonso Reyes, Pasado inmediato, op. cit., p. 151. 
filósofo, místico y político, escritor y maestro, es, sin disputa, la figura intelectual y humana más apasionante que ha producido México", ${ }^{57}$

\section{Don José Vasconcelos: Semblanza}

José Vasconcelos nació en Oaxaca el año de 1882 y durante su niñez vivió en Sásabe, Sonora; Piedras Negras, Coahuila; ciudad de Campeche, Campeche; Toluca, estado de México, y Ciudad de México. En el Ulises Criollo, ${ }^{58}$ su obra autobiográfica, dedica varias páginas a describir esta primera etapa de su formación social e intelectual, sobre todo en la escuela norteamericana de Eagle Pass:

Mi primera experiencia en la Escuela de Eagle Pass fue amarga. Vi niños norteamericanos y mexicanos sentados frente a una maestra cuya idioma no comprendía [...] Durante mucho tiempo, el tono social lo dio Piedras Negras. Nuestra superioridad era notoria en el refinamiento y en el brillo de las fiestas patrióticas, carnavales y batallas de flores de primavera. Pero gradualmente, Eagle Pass adelantaba. ${ }^{59}$

En la Ciudad de México estudió en la Escuela Nacional Preparatoria y posteriormente en la Escuela Nacional de Jurisprudencia. En 1911, presidió el Ateneo de la Juventud y participó al inicio de la re-

${ }^{57}$ Eduardo García Maynez, "Elogio de Vasconcelos", en Memorias del Colegio Nacional, 1960, México, tomo IV, núm. 3, p. 115.

${ }^{58} \mathrm{La}$ obra y el pensamiento de José Vasconcelos se estudia, generalmente, a partir de cuatro de sus trabajos autobiográficos. En esta "biografía novelada", como se ha calificado en alguna ocasión, se reúnen memorias, éxitos y fracasos personales, al tiempo que se interpretan algunos de los acontecimientos más importantes de México después del conflicto revolucionario. Sus trabajos autobiográficos son, en orden cronológico: Ulises criollo: la vida del autor escrita por él mismo (1935); La tormenta: segunda parte del Ulises Criollo (1936), El desastre: tercera parte del Ulises Criollo (1938), El Proconsulado: cuarta parte del Ulises Criollo (1939) y La Flama. Los de arriba en la Revolución. Historia y tragedia (1959). Recomiendo la edición crítica de Claude Fell, pues incluye una cuidadosa introducción, el texto con notas explicativas, una cronología, un estudio histórico sobre el texto, el análisis del texto y un dossier con varios estudios críticos sobre el texto y su recepción.

${ }^{59}$ José Vasconcelos, Ulises Criollo, 2000, Madrid, ALLCA XX, edición crítica de Claude Fell, (coord.), pp. 26 y 49. 
volución como representante de Madero en Washington. ${ }^{60}$ A la caída de Victoriano Huerta fue miembro de la Convención Nacional, como ministro de instrucción de Eulalio Gutiérrez. ${ }^{61}$ Después de la muerte de Venustiano Carranza y del triunfo del Plan de Agua Prieta, en mayo de 1920, los generales sonorenses, Álvaro Obregón y Plutarco Elías Calles gobernaron el país. Para conservar la legitimidad durante el relevo presidencial y evitar una mayor inestabilidad política, los generales rebeldes procuraron guardar las formas legales y estuvieron dispuestos a que el Congreso nombrara un titular como presidente provisional de la República. El presidente interino fue Adolfo de la Huerta (1881-1955), otro miembro del grupo de los sonorenses, que ocupó su cargo del 1 de junio de 1920 al 30 de noviembre del mismo año. ${ }^{62}$ En ese gabinete provisional, José Vasconcelos fue nombrado rector de la Universidad de México y jefe del Departamento Universitario y de Bellas Artes, ${ }^{63}$ el máximo cargo educativo del país, puesto que la Secretaría de Instrucción había sido eliminada por Venustiano Carranza. En octubre de ese mismo año, Vasconcelos propone a la cámara de diputados un Proyecto de Ley para la creación de una Secretaría de Educación Pública Federal. ${ }^{64}$

${ }^{60}$ Cfr. ibid, p. 422; Raúl Trejo Villalobos, Filosofía y vida: El itinerario filosófico de José Vasconcelos, 2010, Salamanca, Ediciones Universidad de Salamanca, pp.154-5.

${ }^{61}$ Cfr. Álvaro Matute, "Dos ateneístas en la Convención de Aguascalientes", en La Soberana Convención Revolucionaria en Aguascalientes, 1914-1989, 1990, Aguascalientes, Gobierno del Estado, Instituto Cultural de Aguascalientes, pp. 116-20.

${ }^{62}$ Cfr. Jean Meyer, La Revolución Mexicana. 1910-1940, 1992, México, Editorial Jus, pp. 72-3; 117; Pedro Castro, La integridad como arma de la revolución, México, 1998, Siglo XXI, pp. 40-1; Luis Aboites y Engracia Loyo, "La construcción del nuevo estado, 1920-1945", en Nueva Historia General de México, México, 2010, Colegio de México, pp. 595-600; y Jean Meyer, "México: Revolución y Reconstrucción en los años veinte", en Leslie Bethel (ed.), Historia de América Latina, vol. 9, México, América Central y el Caribe, c. 1870-1930, 1992, Barcelona, ed. Crítica-Cambridge University Press, pp. 99-105.

${ }^{63}$ José Vasconcelos colaboró del 4 de junio de 1920, hasta el 2 de julio de 1924. En el mismo gabinete, Manuel Gómez Morín se incorpora como secretario particular del Secretario de Hacienda de Adolfo de la Huerta, Salvador Alvarado. Posteriormente, en el gobierno de Álvaro Obregón acepta en enero de 1921 el cargo de Oficial Mayor de la Secretaría de Hacienda. El 21 de julio de 1921 es nombrado, a los 24 años, Subsecretario de Hacienda interino, por encargo de Adolfo de la Huerta y releva a Manuel Padrés. En ese mismo año tiene la necesidad de presentar una Ley del Centenario, que gravaba ingresos y ganancias en el mes de agosto. La ley fue redactada por Miguel Palacios Macedo, quien había sido secretario particular de Padrés.

${ }^{64}$ Proyecto de Ley para la creación de una Secretaría de Educación Pública Federal... op.cit. En la redacción de este proyecto participaron Ezequiel Chávez, Enrique O. Aragón, 
La iniciativa no sólo fue original en materia de reorganización administrativa, sino además representaba un verdadero proyecto cultural que tenía como objetivo instaurar una cultura de masas, en la que los intelectuales y los artistas trabajaran unidos para beneficio de toda la nación. Esta función civilizadora de la nueva Secretaría de Educación Pública tendría que extenderse por todo el territorio, haciendo llegar a cualquiera de sus ciudadanos las diversas expresiones de la cultura. Mediante los libros, el teatro, la música, el acceso a museos y los festivales al aire libre, se daría paso a una renovada cultura popular, a una transformación de la sociedad. ${ }^{65}$

La obra de Vasconcelos en la Secretaría de Educación Pública se interrumpió cuando el presidente Álvaro Obregón aceptó su dimisión, en julio de 1924. La causa que Vasconcelos expuso en su carta de renuncia fue que no se había procedido contra los asesinos de Francisco Field Jurado, el senador que desaprobó los Tratados de Bucareli. ${ }^{66}$ Después de su renuncia, se postuló para la gubernatura de Oaxaca. La decisión fue un rotundo fracaso porque no contaba con el apoyo de la élite gobernante y en las elecciones hubo indicios de fraude. Como respuesta inmediata fundó, junto con su discípulo Manuel Gómez Morín, La Antorcha ${ }^{67}$ un semanario político que representó un espacio de crítica y reflexión contra el régimen. En 1925, cuando José Vasconcelos decidió salir rumbo a Europa, la dirección de la revista quedó en manos de Daniel

Alfonso Caso, Alberto Vázquez del Mercado, Manuel Gómez Morín, Genaro Estrada y Mariano Silva.

${ }^{65}$ Cfr. Enrique Krauze, "Pasión y contemplación en Vasconcelos", en José Vasconcelos, Ulises Criollo, 2000, op. cit., pp. 945-7; y José Álvaro Matute, "La política educativa de José Vasconcelos", en Fernando Solana, et al., Historia de la Educación Pública en México, 1981, México, FCE, pp. 161-82.

${ }^{66}$ María Teresa Gómez Mont, Manuel Gómez Morín, 1915-1939. La raíz y la simiente de un proyecto nacional, 2008, México, FCE, pp. 184. Moisés Sáenz, de tradición protestante, había recibido una formación presbiteriana en el seno familiar y en el Colegio Presbiteriano de Coyoacán.

${ }^{67}$ El primer número de este semanario se publicó el 4 de octubre de 1924; cfr. José Vasconcelos, La Antorcha, semanario politico de José Vasconcelos, México, tomo I, núm. 1, 4 de octubre de 1924. La descripción detallada de su directorio y de los artículos que se incluyeron se pueden verificar en Gómez Mont, op. cit., p. 185. 
Cosío Villegas. ${ }^{68}$ Durante este tiempo se dedicó a visitar algunas ciudades europeas hasta radicarse en París, en donde se esncuentra con Miguel Palacios Macedo. "José Vasconcelos coincidió en su estancia parisina con Miguel Palacios Macedo, cuya amistad amarraría lazos tan fuertes que serían imposibles de desatar. Es Palacios Macedo quien con mayor fidelidad siguió a Vasconcelos en su aventura de 1929". ${ }^{69}$

$\mathrm{Al}$ año siguiente, en 1926, regresa al continente americano para dictar varias conferencias, primero en la Universidad de Puerto Rico y después en República Dominicana, bajo los auspicios del Ministerio de Educación. ${ }^{70}$ Regresó a México después de la muerte de Álvaro Obregón y lanzó su candidatura a la Presidencia de la República, apoyado por sus amigos, exalumnos y el partido antireeleccionista.

El vasconcelismo tuvo un amplio impacto en el ámbito urbano [...] contó con la participación de múltiples sectores sociales tales como jóvenes de clase media, obreros, grupos indígenas de diferentes etnias, trabajadores de los ingenios, intelectuales de distintas localidades del país, mujeres organizadas en clubes, estibadores, campesinos, antiguos revolucionarios de varias facciones, gente humilde, trabajadores petroleros entre otros. El gobierno intensificó la represión cuando el vasconcelismo creció. Vasconcelos pensó seguir el ejemplo de Madero, esperar el resultado de las elecciones y, en caso de fraude, convocar a un levantamiento armado. Sin embargo, las condiciones de 1929 no eran las de 1910 [...] Las cifras oficiales de la elección fueron: Pascual Ortiz Rubio, 93.58\%, José Vasconcelos, 5.42\%, Rodrigo Triana, 1.01\% [...] Este fue el inicio del predominio del partido oficial. Los asesinatos de los seguidores de Vasconcelos en Topilejo cerraron trágicamente este capítulo de nuestra historia. ${ }^{71}$

${ }^{68} \mathrm{http}$ ://www.colegionacional.org.mx/SACSCMS/XStatic/colegionacional/template/ content.aspx ?mi $=163 \&$ se $=$ vida\&te $=$ detallemiembro y http://www.conaculta.gob.mx/sala prensa_detalle.php?id=19495 [30 de noviembre de 2012].

${ }^{69}$ Gómez Mont, op. cit., p. 279.

${ }^{70}$ Vasconcelos agrupó estas conferencias bajo el título de Indología.

${ }^{71}$ María Julia Sierra Moncayo y Reynaldo Sordo Cedeño, Atlas Conmemorativo. 1810-19102010, 2010, México, Siglo XXI editores-Senado de la República, p. 216. 
Después de su derrota, Vasconcelos volvió al exilio y regresó a México hasta 1940; durante este período recibió los doctorados honoris causa de las universidades de Puerto Rico, Chile, Guatemala y El Salvador. Abandonó la política y se dedicó al cultivo de la historia y de obras de contenido filosófico. Esta semblanza de su vida nos muestra un personaje controvertido y polémico, cuya obra y sus múltiples influencias todavía no se han aquilatado lo suficiente. Sin embargo, defensores y detractores reconocen la importancia de su obra educativa, como una de las más ambiciosas que se realizó en el México de siglo XX. ${ }^{72}$ José Vasconcelos murió el año de 1959.

\section{Los libros y el proyecto educativo}

José Vasconcelos fue el hombre que en 1921 encarnó las aspiraciones de la revolución, tal y como lo describe Daniel Cosío Villegas. ${ }^{73}$ No sólo era un hombre de acción, sino un verdadero "intelectual”, un hombre de libros, que tuvo la confianza y los recursos que le proporcionó el nuevo régimen.

Esa conjunción de circunstancias, tan insólita en nuestro país, produjo también resultados inesperados; tanto, que en México hubo entonces una como deslumbradora aurora boreal, anuncio del nuevo día [...] Entonces se sentía fe en el libro, y en el libro de calidades perennes; y los libros se imprimieron a millares, y a millares se obsequiaron. Fundar una biblioteca en un pueblo pequeño y apartado parecía tener tanta significación como levantar una iglesia y poner en su cúpula brillantes mosaicos que anunciaran al caminante la proximidad de un hogar donde descansar y recogerse. ${ }^{74}$

El primer impulso que tuvo el proyecto educativo de Vasconcelos provino del extraordinario presupuesto que le dispensó el presidente Mexico, FCE.

${ }^{72}$ Cfr. Martha Robles, Entre el poder y las letras: Vasconcelos en sus Memorias, 2002,

${ }^{73}$ Daniel Cosío Villegas colaboró con José Vasconcelos desde el Departamento de Publicaciones que se fundó en la Secretaría de Educación Pública; posteriormente, en el Departamento de Extensión Universitaria y al fin coordinó el Semanario la Antorcha cuando Vasconcelos abandonó el país.

${ }^{74}$ Daniel Cosío Villegas, Extremos de América, 2004, México, FCE, pp. 35. Cursivas mías. 
Álvaro Obregón entre los años 1920 y 1924. Sin embargo, esos planes no hubieran podido realizarse sin la generosa colaboración de los más destacados intelectuales de la época del Ateneo y de la Generación de 1915. ${ }^{75}$ Apoyado en estos recursos y en el talento de sus colaboradores, emprendió un vasto proyecto de alfabetización orientado a brindar una educación general y sistematizada para la población. Se estima que el analfabetismo afectaba, en ese momento, a 77\% de la población. ${ }^{76}$ En segundo lugar, comienza la instalación de nuevas escuelas y la reestructuración de las existentes, que se encontraban desarticuladas y en severos problemas de mantenimiento. Merecen mención especial, la creación del Departamento de Extensión Universitaria (1922) $)^{77}$ que ofrecía "instrucción" a todos aquellos que habían concluido los estudios de primaria, y la fundación de la Escuela de Verano (julio de 1923) para estudiantes extranjeros. Esta escuela llegó a matricular a más de 600 estudiantes y profesores procedentes de Estados Unidos y fue coordinada por Pedro Henríquez Ureña.

En tercer lugar, inspirada en la mística y el servicio de los misioneros del siglo XVI, emprendió un ambicioso proyecto editorial y la fundación de bibliotecas a lo largo y ancho de todo el país, incluso en las serranías. ${ }^{78}$ Apunta Jean Meyer al respecto:

Supo insuflar en sus colaboradores un verdadero espíritu de cruzada y organizar, inspirándose en los franciscanos del siglo XVI, las "misiones

${ }^{75}$ Cfr. Enrique Krauze, Los caudillos culturales de la Revolución mexicana, 2008. México, Siglo XXI editores, pp. 104-123. Según Jean Meyer, José Vasconcelos recibió en 1920, 38 millones de pesos, cuando el presupuesto nacional se acercaba a 350 millones. Hasta ese momento era el presupuesto más grande de la historia en materia educativa.

${ }^{76}$ Cfr. Luis Aboites y Engracia Loyo, "La construcción del nuevo estado, 1920-1945", op. cit., p. 601.

${ }^{77}$ Cfr. Claude Fell, José Vasconcelos, Los años del Águila, op. cit., pp. 299; 301. En el Departamento de Extensión Universitaria se impartían conocimientos técnicos y prácticos, y una formación en ciencias sociales para que el trabajador conociera sus deberes y derechos como ciudadano; incluía los cursos por correspondencia y las clases nocturnas. Daniel Cosío Villegas fue el responsable del departamento y organizó con poco éxito las conferencias en escuelas nocturnas.

${ }^{78}$ Cfr. Claude Fell, José Vasconcelos, Los años del Águila, op. cit., p. 290. En el contexto de los cursos de verano, se formó una comisión integrada por Vicente Lombardo Toledano, Pedro de Alba y Daniel Cosío Villegas que otorgaba becas a los estudiantes para concluir sus estudios en México o en el extranjero. El director de la Escuela de Verano era Pedro Henríquez Ureña, que renunciará el 21 de agosto de 1923. 
rurales", grupos de voluntarios que iban a las regiones más aisladas para que todo México fuera abarcado a la vez. ${ }^{79}$

Como se dijo anteriormente, desde que se presentó El proyecto de ley para la creación de la Secretaría de Educación Pública, el 22 de octubre de 1920, Vasconcelos insistía en que "los libros grandes y generosos del pasado" son una ventana que se abre, una torre elevada en la que se puede mirar el vasto edificio. En esos libros y en la escuela aprendemos a distinguir y a juzgar de modo que podemos apreciar lo que vale la pena. Según Vasconcelos, sólo en el vehículo generoso de los libros encontramos el tesoro de la cultura humana; los libros "nos dan las ideas, la riqueza, la prodigalidad entera de la conciencia" ${ }^{80}$ Según The Oxford History of México:

Vasconcelos atacó de frente el problema más grande. Con generosas asignaciones en el presupuesto nacional durante dos años, la SEP comenzó a crear un sistema nacional de escuelas primarias rurales. Institutos de formación docente itinerantes, llamados misiones culturales, viajaron de pueblo en pueblo; se construyeron inmuebles para escuelas, se establecieron bibliotecas y se organizaron comités para mejorar escuelas y comunidades. Los profesores fueron capacitados en temas académicos, en métodos de enseñanza, salud y nutrición, deporte, música, agricultura, artes mecánicas y más. Para el largo plazo, la SEP estableció un sistema de escuelas rurales secundarias que proveían alojamiento y comida, educación y capacitación de forma gratuita. La SEP también publicó ediciones baratas de los grandes libros de la civilización occidental y los colocó en miles de pequeñas bibliotecas en pueblos y ciudades. ${ }^{81}$

En la Casa editorial de la Universidad Nacional se publicaron, entre los años 1921 y 1924, Los Clásicos. De acuerdo con el plan inicial, super-

${ }^{79}$ Cfr. Jean Meyer, La Revolución Mexicana. 1910-1940, op. cit., p. 121.

${ }^{80}$ Proyecto de Ley para la creación de una Secretaría de Educación Pública Federal... op. cit.; y Álvaro Matute, et al., (comps.), José Vasconcelos: de su vida y su obra. Textos selectos de las jornadas vasconcelianas de 1982,1984, México, UNAM, pp. 35.

${ }^{81}$ William Beezley y Michael Meyer, The Oxford History of Mexico, 2012, New York, Oxford University Press, pp. 450-1. Cursivas y negrillas mías. 
visado directamente por Vasconcelos, se tenía la intención de editar por lo menos 32 volúmenes en tirajes de 30 mil ejemplares para cada uno. Eso implicaba la revisión y la traducción de las obras clásicas. ${ }^{82}$

El encargado de las ediciones fue Julio Torri, y en este apresurado proceso participaron Antonio Caso, Pedro Henríquez Ureña, Manuel Gómez Morín, Daniel Cossío Villegas, Vicente Lombardo Toledano, entre otros. Cada libro tuvo un tiraje de 20 a 25 mil ejemplares. Se publicaron los siguientes títulos: Romain Rolland, Vidas ejemplares; Goethe, Fausto; los Diálogos de Platón en 3 tomos; las Tragedias de Esquilo, de Sófocles y de Eurípides; de Plutarco, las Vidas Paralelas en 2 tomos; Los Evangelios; La Divina Comedia; las Enéadas de Plotino; de Homero, la Ilíada en 2 tomos y la Odisea; de Tagore, La Luna Nueva; y de Tolstoi, Cuentos Escogidos. ${ }^{83}$

En 1923 se añade la antología de Gabriela Mistral, Lecturas para mujeres y la publicación de algunos folletos de divulgación. La Secretaría de Educación Pública también distribuyó, sin costo, alrededor de un millón de reproducciones del Libro nacional de escritura-lectura, dos millones de álbumes de alfabetización, cerca de 100 mil ejemplares de la Historia Patria de Justo Sierra y dos volúmenes de literatura universal, Lecturas Clásicas para niños, como texto para la introducción de los Clásicos infantiles en las escuelas. En el año 1924 se ofreció una serie de antologías de obras de autores hispanoamericanos, como José Martí, Vicente Riva Palacio, Ricardo Palma, Manuel Gutiérrez Nájera, Salvador Novo, Carlos Pellicer y Alfonso Reyes, entre otros. A este trabajo de edición se deben sumar las revistas El Maestro, con un tiraje de 5,000 mil ejemplares al mes y El Libro y el Pueblo. ${ }^{84}$

Según Claude Fell, Los Clásicos distribuidos entre 1921 y 1924, se pueden calcular en 130,000 o 140,000 ejemplares, una cantidad que no representa ni la mitad del número de ejemplares que se im-

${ }^{82}$ Cfr. Claude Fell, José Vasconcelos, Los años del Águila, op. cit., pp. 488; 492.

${ }^{83} \mathrm{Un}$ texto que profundiza sobre los antecedentes, circunstancias, naturaleza y cantidad de las obras que fueron publicadas por José Vasconcelos es: Engracia Loyo, "Lectura para el pueblo, 1921-1940”, en Historia Mexicana, 1984, vol, 33, núm.3, pp. 298-345.

${ }^{84}$ Cfr. Linda Sametz Remba, Vasconcelos, el hombre del libro. La época de oro de las bibliotecas, 1991, México, UNAM, pp. 227 
primieron. De la Ilíada, por ejemplo, se imprimieron 38,940 ejemplares. ${ }^{85}$ En sus memorias, Vasconcelos comenta:

En broma dije a Obregón un día:

Lo que este país necesita es ponerse a leer La Ilíada. Voy a repartir cien mil Homeros en las escuelas nacionales y en las bibliotecas que vamos a instalar [...] Pero ¿de dónde iba a sacar cien mil ejemplares de la Ilíada, otros tantos de la Odisea, y así sucesivamente, las toneladas de los cien mejores libros existentes? Hacer el pedido a las editoriales españolas, únicas que hubieran podido servirlo, demandaba tiempo y daba lugar a que alguien ganara comisiones que aumentarían considerablemente los precios. En consecuencia, lo obvio, lo comercial y lo patriótico era aprovechar las prensas del Gobierno. ${ }^{86}$

Debajo de esta trepidante actividad literaria latía la convicción de que la verdadera educación coloca en el centro de su quehacer al hombre en la totalidad de sus dimensiones, lo invita al diálogo crítico sobre los fines de su actividad y le posibilita el acceso a la riqueza acumulada de la cultura y de la historia. Es una educación libre y para hombres libres, sin menoscabar el hacer y la técnica. Para Vasconcelos, la educación no se opone al aprender haciendo, pero de ningún modo piensa que sea suficiente para hacerse hombre. La miopía está en concebir los sistemas educativos solamente en términos prácticos, ya que la educación cumple una función trascendente, estética e incluso espiritual, que resulta imprescindible en la orientación cósmica del hombre. ${ }^{87}$

Las lecturas clásicas darán al alumno lo que a menudo la escuela le niega: un destino en proceso [...] Ahora me dirijo a los 90 millones de hispanoamericanos, libres de bastardaje mental, y les recuerdo que sus antepasados, desde la infancia, gustaban de los clásicos griegos, leían a los latinos, se acercaban a las cumbres del espíritu humano, aunque todavía no poseyeran la máquina de calcular, el tractor de gasolina o el altoparlante. Nada me parece más urgente que acercar a la juventud, desde

${ }^{85}$ Cfr. Claude Fell, José Vasconcelos. Los Años del Águila, 1989, op. cit., p. 490.

${ }^{86}$ José Vasconcelos, El Ulises Criollo. El desastre, 1951, México, Ediciones Botas, pp. 51.

${ }^{87}$ Cfr. Claude Fell, José Vasconcelos, Los años del Águila, op. cit., p. 181. 
la infancia, a los grandes modelos de todos los tiempos. No hay mejor cura para la mediocridad de la época. Y no posee la civilización elementos más poderosos de florecimiento que la constante comunión con los valores supremos que ha engendrado la especie. Todo el ambiente de una escuela puede transformarse y ascender con una prudente dosis de buena lectura sólida de clásicos: Homero, Platón, Dante, los universales, y, para nuestro uso, Cervantes, Calderón, Lope de Vega y Galdós, el último. ${ }^{88}$

Cuando Vasconcelos defiende el estudio de los Grandes Libros no está secundando una nostalgia libresca que se refugian en las abstracciones y colecciona citas, referencias y datos, típicos de la mentalidad enciclopédica y erudita. Tampoco critica per se a la ciencia y a la técnica, sino al reduccionismo epistemológico que las imagina como únicas dimensiones del hombre. Reivindica el auténtico cultivo de las letras, que permite a los hombres el examen crítico de uno mismo, de su propia historia y tradición.

Tal y como había sucedido en la Europa cristiana y como lo habían tratado de hacer los misioneros del siglo XVI, hijos de la universidad, del libro y del cristianismo que la parió, la universidad encontraba por vez primera en México su vocación. Si ella había nacido con el libro y el libro, para desgracia del país, había servido sólo para encumbrar una clase que explotaba a una población que en 1920 tenía $80 \%$ de analfabetas y que había hecho estallar la Revolución; ahora, esa misma universidad, redescubriendo su verdadera vocación, se convertía en el motor que ponía el alfabeto, los libros y su saber al servicio de todos; civilizar la nación, hacerla entrar en la dinámica no de una grandeza económica, sino trascendente, que estaba en el propio corazón del mestizaje. ${ }^{89}$

Ese diálogo con los grandes autores fomenta la imaginación, la sensibilidad estética, la solidaridad y la búsqueda de un ideal ennoblecedor para el individuo y para la sociedad. Sin embargo, para que la lectura de

${ }^{88}$ José Vasconcelos, De Robinson a Odiseo, pedagogía estructurativa, 2002, México, Senado de la República, p. 88. Cursivas y negrillas mías.

${ }^{89}$ Javier Sicilia, José Vasconcelos y el espíritu de la Universidad, 2001, México, UNAM, pp. 29-30. 
los "grandes libros" fuera fructífera, era necesario que la disciplina escolar dispensara los métodos para alcanzar y hacer propio las cumbres de las humanidades y las artes. Dice José Vasconcelos:

No se puede dar una norma fija; pero lo cierto es que el funcionamiento mismo va determinando normas de lectura que establecen hábitos y apuntan métodos $[. .$.$] Únicamente la disciplina escolar orienta la lectura de$ modo que conduzca a la perfección de un panorama extenso, pero ordenado, del saber. La carencia de una disciplina general rigurosa pone al autodidacta en condiciones de inferioridad sobre el escolar. Y una de las funciones más importantes de la escuela es vencer la anarquía de los lectores indoctos. Quien elige al azar no puede, por falta de método, descubrir siquiera sus verdaderas preferencias [...] La regla de oro aquí, como en toda estimación del saber, consiste en referirse a las cumbres del alma para tomar el nivel del esfuerzo y del libro. ${ }^{90}$

Se impone, entonces, la síntesis de vida intelectual y vida práctica. No basta ser un intelectual si no se transforma la realidad. No se puede transformar la realidad sin el rigor intelectual. La vida de Vasconcelos, de sus discípulos y colaboradores, en especial de Manuel Gómez Morín, Miguel Palacios Macedo y Daniel Cossío Villegas, parece empeñada en alcanzar este objetivo; la unión de la filosofía, la historia y las letras con la acción política y la técnica. Señala don José:

La escuela libresca es deficiente, pero una escuela que reemplaza el libro con el útil condena a la mayoría de la especie a no conocer jamás el mundo de las ideas. La vida, al fin y al cabo, obliga a la mayoría a usar las manos y enseña a usarlas, pero el uso de los libros únicamente la escuela puede darlo. De donde se infiere que es menos nociva, menos imperfecta una escuela nada más libresca que una escuela nada más técnica. En la vida hay, al fin y al cabo, pasiones y casos que despiertan el alma; en cambio, una escuela sin enseñanza desinteresada, independiente de la inmediata adaptación a la práctica, sería una escuela destinada a consumar el degüello del alma. ${ }^{11}$

${ }^{90}$ José Vasconcelos, De Robinson a Odiseo..., op. cit., p. 88. Cursivas mías.

${ }^{91}$ Idem, p. 39. Cursivas mías. 


\section{José Vasconcelos en la Universidad de Chicago}

Después de la renuncia de Vasconcelos a la Secretaría de Educación Pública en el año de 1924, la secretaría quedó en manos de Moisés Sáenz, un hombre que había sido alumno de John Dewey ${ }^{92}$ en el Teachers ' College de la Universidad de Columbia; hacía hincapié en la escuela "de la acción", la educación de tipo práctico, en la que los niños aprenden a trabajar y a vivir, y "sólo secundariamente a leer y escribir". No está de más advertir que esta "escuela nueva", de talante pragmatista, fue recibida inicialmente con expectación y optimismo, incluso fue promovida por Vasconcelos, que nombró a Eulalia Guzmán (1890-1985) jefa del primer Departamento de Alfabetización y la apoyó en su proceso de especialización en ciencias de la educación en Berlín y Jena. ${ }^{93}$ Sólo más tarde, las élites intelectuales cuestionarían los planteamientos de esta escuela activa, como el mismo Vasconcelos con vehemencia en De Robinson a Odiseo. Pedagogía Estructurativa. ${ }^{94}$

En Estados Unidos, la influencia de la filosofía de la educación de John Dewey fue profunda y duradera. Sus obras, The School and Society (1889), How we think (1910), Democracy and education (1916) y Experience and Education (1938), dominaron la discusión sobre los fines que debería perseguir la universidad americana. Incluso, en 1894 Dewey fue invitado por el presidente de Universidad de Chicago (fundada en 1890), William Rainey Harper (1856-1906) a incorporarse a la universidad. Dos

${ }^{92}$ John Dewey fue fundador del pragmatismo y uno de los filósofos más importantes de la primera mitad del siglo XX. Sus planteamientos educativos fueron ampliamente reconocidos e influyeron de manera decisiva en el diseño y contenidos de la educación norteamericana. Cfr. John Dewey, The School and Society, 2008, New York, Cosimo; How we think, 2008, New York, Cosimo; Democracy and education, 2010, Los Angeles, Indo-European Publishing; Experience and education, 1998, West Lafayette, Ind., Kapa Delta Pi; y Henry Edmonson, John Dewey and the decline of American education: how the patron saint of schools has corrupted teaching and learning, 2006, Wilmington, ISI Books.

${ }^{93}$ Cfr. Eulalia Guzmán, La escuela nueva o de la acción, 1923, México, Editorial Cultura, pp.1-46.

${ }^{94}$ Cfr. José Vasconcelos, De Robinson a Odiseo... op. cit.; pp.41-43; y José Antonio Aguilar Rivera, La sombra de Ulises, 1998, México, CIDE-Miguel Ángel Porrúa, p. 34. En 1935, José Vasconcelos publica un trabajo de pedagogía en el que polemiza con la filosofía de la educación de John Dewey; sin duda es un documento muy atractivo para los investigadores que quieran conocer con mayor profundidad la filosofía de la educación del fundador de la SEP. 
años después, en 1896, funda la University of Chicago Laboratory School, la Escuela Experimental de la Universidad..$^{5}$

La controversia que se desató contra el pragmatismo en la educación universitaria en la década de 1930 en los Estados Unidos tuvo en la misma Universidad de Chicago su epicentro, con las críticas realizadas por Robert Hutchins y Mortimer Adler a los postulados que prevalecían en la educación norteamericana. ${ }^{96}$ Un ejemplo emblemático es la obra de Hutchins, The Higher Learning in America ${ }^{97}$ y todas las publicaciones de Mortimer Adler. ${ }^{98}$ El proyecto educativo de Hutchins-Adler se opuso con firmeza al pragmatismo educativo y al positivismo..$^{99}$ Aunque Hutchins no tuvo acceso directo al pensamiento de Dewey, conoció de segunda mano las interpretaciones de Adler y sus desacuerdos con la filosofía educativa de Dewey se pueden verificar en las páginas de Social Frontier. ${ }^{100}$

${ }^{95}$ Cfr. Jay Martin, The education of John Dewey: a biography, 2002, New York, Columbia University Press, pp. 176-7.

${ }^{96}$ Cfr. William McNeill, Hutchin's University. A memoir of the University of Chicago, 1991, Chicago, University of Chicago Press, pp. 16-40.

${ }^{97}$ Cfr. Robert Hutchins, The Higher Learning in America, 1933, New Haven, Yale University Press; The University of Utopia, 1953, Chicago, University of Chicago Press; y Education for Freedom, 1943, Baton Rouge, Lousiana State University Press.

${ }^{98}$ Cfr. Mortimer Adler, The Paideia Proposal. An educational manifesto, New York, Simon \& Schuster, 1998, pp. 4; How to speak, how to listen, 1997, NY, Simon \& Schuster; Manual for discussion leaders, 1946, Chicago, University of Chicago Press; y et al., How to read a book, 1972, NY, Simon \& Schuster.

${ }^{99}$ Cfr. Mary Ann Dzuback, Robert M. Hutchins. Portrait of an Educator, op. cit., p. 179; y Milton Mayer, Robert Maynard Hutchins. A Memoir, op. cit., pp. 116-28.

${ }^{100}$ Esta publicación se convirtió en la revista educativa más importante desde la Gran depresión. El primer número se publicó en 1934 por iniciativa de un grupo de estudiantes y maestros del Teachers' College de la Universidad de Columbia, e incluyó a George Counts y William Heard Kilpatrick. La revista representó un testimonio de la reconstrucción política y social en Estados Unidos durante ese período. Se publicó durante nueve años e incorporó artículos de los más grandes pensadores sociales y educativos; en ella, Dewey escribió una crítica a la obra de Robert Hutchins, The Higher Learning in America, la réplica del rector de la Universidad de Chicago y varios artículos de Mortimer Adler; vg. John Dewey, "The Higher Learning in America", The Social Frontier, volume 3, núm. 24, March, 1937, pp. 167-169; Robert Hutchins, "Proposals to Remake Higher Education", The Social Frontier, volume 3, núm. 22, 1937, pp. 103-104; Robert Hutchins, "The Crisis in Contemporary Grammar, Rhetoric, and Mr. Dewey", The Social Frontier, vol. 3, núm, 23, 1937, pp. 137-9; M. Adler, "The crisis in contemporary education", The Social Frontier, vol. V, núm. 42, february, 1939, pp. 140-5; y Eugène Provenzo (ed.), Social Frontier. A Critical Reader, 2011, New York, Peter Lang Publishing, pp. 1-18. 
La Universidad de Chicago, invitó en 1926 a José Vasconcelos para pronunciar una serie de conferencias, redactadas y dictadas en inglés, bajo el título de Aspects of the Mexican Civilization ${ }^{101}$ y a impartir la cátedra de Sociología hispanoamericana como profesor visitante. ${ }^{102}$ Lo más probable es que su presencia despertara una buena dosis de interés y admiración, porque tenían la oportunidad de escuchar al hombre que había encabezado uno de los más grandes esfuerzos civilizatorios en la historia de México y del mundo occidental durante los últimos siglos. Según Ilan Stavans:

Su influencia es todavía palpable hoy en día, especialmente en el debate referente a las teorías raciales, y mucho más en los círculos académicos en los Estados Unidos que en sus contrapartes en América Latina, incluyendo México. Como secretario de educación, Vasconcelos fue una pieza clave en la construcción del sistema educativo que permitió a México convertirse en una nación moderna. ${ }^{103}$

La presencia de Vasconcelos ocurrió dos años antes de que Robert Hutchins asumiera la presidencia de la Universidad de Chicago, en abril de 1929, y se diera inicio a un largo proceso de reformas dentro de la universidad. ${ }^{104}$ En 1930, el nuevo rector de Chicago, de tan sólo 30 años, invitó a Mortimer Adler a participar en la renovación de la educación liberal mediante la difusión y enseñanza de los Grandes Libros. Es interesante constatar que Vasconcelos, desde 1921, ocho años antes de que Robert Hutchins llegara a Chicago, ya se había preocupado de reunir, traducir, publicar y difundir masivamente un muestrario de los libros fundamentales. ${ }^{105}$ Afirma Vasconcelos:

[sc. En los grandes libros] está vivo eternamente lo fundamental del hombre en cuanto hombre, sobre diferencias de tiempos y razas [...] Deseo

${ }^{101}$ José Vasconcelos y Manuel Gamio, Aspects of Mexican Civilization, 1926, Chicago, University of Chicago Press.

${ }^{102}$ Cfr. José Antonio Aguilar Rivera, La sombra de Ulises, op. cit., p. 26.

${ }^{103}$ Cfr. Ilan Stavans, José Vasconcelos. The prophet of race, 2011, New Brunswick, NJ, Rutgers University Press, p. 3.

${ }^{104}$ Cfr. José Antonio Aguilar Rivera, La sombra de Ulises, op. cit., p. 25.

${ }^{105}$ Ibid., p. 34. 
hacer llegar el libro excelso a las manos más humildes y lograr de esta manera la regeneración espiritual que debe preceder a toda regeneración. ${ }^{106}$

El proyecto editorial de Vasconcelos fue completamente original. No sólo intentó reunir esos "grandes libros", para que un selecto grupo de privilegiados se aprovechara de ellos, sino que buscó divulgarlos entre las masas populares. La intención era ofrecer al pueblo una oportunidad de regeneración a partir de una experiencia civilizatoria. ${ }^{107}$

Hasta aqui la primera parte de una investigación en curso, cuyos resultados - espero- serán objeto de entregas subsecuentes en esta revista.

${ }^{106}$ José Vasconcelos, “Cómo se hizo la Ilíada en la Universidad”, 1922, en El libro y el pueblo, año 1 , núm. 1, p. 4.

${ }^{107}$ Cfr. Edgar Llinás, "Vasconcelos como promotor de una educación liberadora", en Álvaro Matute et al. (comps.), José Vasconcelos: de su vida y su obra..., op. cit., pp. 170-180. 
CITAM Derechos Reservados.

La reproducción total o parcial de este artículo se podrá hacer si el ITAM otorga la autorización previamente por escrito. 